\title{
Article
}

\section{Gendered Experiences of Living with HIV in Australia}

\author{
Vicki Hutton
}

check for updates

Citation: Hutton, V. Gendered Experiences of Living with HIV in Australia. Sexes 2021, 2, 244-255. https://doi.org/10.3390/sexes2030020

Academic Editor: David L. Rowland

Received: 23 May 2021

Accepted: 22 June 2021

Published: 24 June 2021

Publisher's Note: MDPI stays neutral with regard to jurisdictional claims in published maps and institutional affiliations.
Discipline of Counselling, Australian College of Applied Psychology, Melbourne 3000, Australia; vicki.hutton@acap.edu.au

\begin{abstract}
Globally, women represent more than half the people living with HIV. This proportion varies by country, with an over-representation of HIV among men who have sex with men (MSM) in some regions. For example, in Australia, MSM account for over $60 \%$ of transmissions, with heterosexual sex accounting for almost a quarter of transmissions. Irrespective of geographic region, there is evidence that women can have a different lived experience of HIV due to their unequal social and economic status in society, while MSM can have a different lived experience depending on the laws and customs of their geographic location. Gender differences related to risk factors, stigma, access to services, mental health, health-related quality of life and economic consequences have been consistently reported globally. This paper explores the subjective lived experience of gender and sexuality disparities among three individuals living with HIV in Australia: a male who identified as gay, and a male and female who each identified as heterosexual. Analysis of themes from these three case reports indicated discernible differences by gender and sexuality in four areas: access to medical services, social support, stigma and mental health. It is argued that knowledge and understanding of potential gender and sexuality disparities must be factored into supportive interventions for people living with HIV in Australia.
\end{abstract}

Keywords: gender; sexuality; HIV; AIDS; stigma

\section{Introduction}

Epidemiological patterns among the 38 million people currently living with HIV worldwide indicate that their lived experience can differ according to a mix of factors including gender, sexuality, region, race, age and income [1]. For example, in sub-Saharan Africa, the majority of new HIV diagnoses result from heterosexual intercourse, with women who have experienced physical or sexual intimate partner violence up to one and a half times more likely to acquire HIV [2]. While women account for more than 50 per cent of people living with HIV worldwide [3], this proportion varies by country, ranging from around 10 per cent in Australia [4] to 25 per cent in USA [5], to girls aged 15 to 19 years accounting for five in six new infections in sub-Saharan Africa [1]. Among males, area of residence and sexuality can play a key factor in how they contracted HIV. In higher income countries such as North America, Western Europe, Australia and New Zealand, men who have sex with men (MSM) have dominated epidemiological patterns of HIV transmission since the start of the pandemic in the 1980s [6].

Global research suggests that women may have a different lived experience of HIV due to their unequal social and economic status in society [2], while MSM may have a different lived experience depending on the laws and social norms of their geographic location [7]. As the physical challenges of living with HIV have been mitigated for the approximately two-thirds of people with access to antiretroviral therapies [1], other difficulties reported by people with HIV can be socially mediated and perceived differently by MSM, men who have sex with women and women [7]. Therefore, an understanding of gendered experiences in areas such as stigma, access to services and mental health can be important when responding to the challenges of supporting people living with HIV. 
In Australia, where the majority of the estimated 28,000 people living with HIV are gay or bisexual men, and 91 per cent of those diagnosed are receiving treatment [8], there is consistent evidence that men and women may experience many differences in their lived experience of HIV. The HIV Futures 9 [4], part of an ongoing study since 1997 of quality of life among people living with HIV in Australia, reported that women-perceived as a lower-risk group - test less frequently than males, are diagnosed later and face additional barriers to viral suppression. They were also more likely to face financial distress, and experience multiple mental health issues (with anxiety and depression being the most common co-morbidities). The previous HIV Futures 8 report [9], when drawing attention to the approximately 3000 women living with (diagnosed) HIV in Australia, confirmed that the experience of living with HIV can be very different for women compared to men. The report identified that some women living with HIV may be more isolated from services or other people living with HIV, and approach their HIV treatment, care and needs differently to the majority group of gay males. Acknowledging that support services and networks often have some programs for women, the focus by necessity remains where the majority of the epidemic falls, which is communities of gay men. This was particularly evident in relation to services, relationships and women's feelings about HIV disclosure and stigma. Men who identified as 'heterosexual or straight' were even less represented than women in the latest HIV Futures 9 [4], raising the possibility that heterosexual males may also be a minority group in Australia at risk of isolation from services and other people living with HIV.

The current paper explores the subjective lived experience of gender and sexuality disparities among three individuals living with HIV in Australia: a male who identified as gay, and a male and a female who each identified as heterosexual. Similarities and differences in their lived experiences and perceptions are analyzed to identify themes related to gender, sexuality and living with HIV. It is argued that knowledge and understanding of potential gender and sexuality disparities must be factored into interventions for access to services, stigma reduction and the mental health of people living with HIV.

\section{Materials and Methods}

Three case reports are presented next, portraying the perspective of a heterosexual female, a heterosexual male and a gay male. These three individuals were responders in a larger online cross-sectional quantitative study conducted in the early 2010s on subjective wellbeing and stigma when living with HIV in Australia. For the quantitative study, HIVpositive individuals aged 18 years and over were invited by recruitment flyers distributed through Australian capital city AIDS councils, hospital infectious disease (ID) clinics, support services for people living with HIV, and HIV community newsletters to participate in an anonymous online survey using the online survey software, SurveMonkey [10]. At the end of the survey, responders were invited to complete an expression of interest if they wished to be interviewed at a later date about their experiences of living with HIV. The expression of interest was submitted separately to the anonymous survey.

There were 128 completed surveys, with over 90 per cent of responders describing themselves as gay males, in keeping with the over-representation of HIV diagnoses among men who have sex with men and the gay communities in Australia. Thirty responders expressed interest to be interviewed and were sent additional information about the interview phase of the study. After reading this information, 28 responders (22 gay males, three heterosexual females and three heterosexual males) provided informed consent for the interviews about their experiences of living with HIV in Australia to proceed at the conclusion of the quantitative study and over a period of 18 months. The three individuals described in the current paper were selected as representative of the three demographic responder groups in the qualitative study, and met two criteria: (1) all three received a formal HIV diagnosis at a similar time to minimize disparities in the medical management of HIV; and (2) they provided detailed gender- and sexuality-related information both unprompted throughout the interview as well as in response to the open-ended general 
question asking if there was anything further they wished to add on their experiences as a gay male/heterosexual female/heterosexual male living with HIV in Australia. As there were no lesbian or transgender responders in the study, these groups could not be included here. This is addressed in the study limitations section.

The three interviews were conducted in private rooms at HIV support service venues. The 60-minute interviews were audio-taped, transcribed and analyzed manually using thematic analysis techniques.

\section{Data Analysis}

This paper adopted an inductive approach using Braun and Clarke's [11] reflexive thematic analysis. While coding and themes were driven by the data content, it was also recognized that themes cannot exist separately to the researcher, being mediated by all that the researcher brings to the process in terms of values, skills and training. With the analytic focus on identifying themes among the three responders' heterogeneous lived experiences and locating those themes within the wider social context [11], reflexive thematic analysis was felt appropriate for the research aims. Since the emergence of HIV, it has been widely recognized that there is no one HIV epidemic, as so many variables affect the lived experience (for example, region of residence, age, gender, sexuality, income, race, ethnicity). Therefore, the epistemological assumption underpinning this qualitative study is that the knowledge is known through the subjective experiences of individuals.

The six phases of reflexive thematic analysis-familiarization; coding; generating initial themes; reviewing and developing themes; refining, defining and naming themes; and writing up-were adhered to in this analysis. Familiarization with the data was achieved through transcribing, reading and re-reading the transcripts. In keeping with the principles underpinning reflexive thematic analysis, coding was approached as providing the building blocks for themes, rather than the process of searching for evidence. It was also acknowledged that coding is a subjective process that required the researcher to constantly reflect on their assumptions and the effects this may have on the shaping of the coding and, therefore, the themes. In this paper, a theme is defined as being able to capture 'something important about the data in relation to the research question' [12] (p. 82); that is, in relation to the gendered experiences of living with HIV. Reflexive thematic analysis is a recursive process, moving backwards and forwards across the phases to include data that, on the surface, may appear dissimilar, but are united by implicit meaning [11]. Using this process resulted in four themes across the data with common, recurring patterns of relevance to the research aim and located within a central organizing concept. While the interviewees seemed to be reporting different experiences within these themes, they were located within the lived experience of gender, sexuality and HIV. These themes were: access to medical services; social support; stigma; and mental health.

All interviewee names and key identifying features have been removed. This study was approved by the Monash University Human Research Ethics Committee (Ethics code CF09/1014-2009000505).

\section{Results}

Results from the three case reports provide a snapshot of different perspectives of a person's meaning-making around HIV, gender and sexuality. Interviewees' ages ranged from 35 to 55 years, and all had been diagnosed with HIV around 2010. (Similar year of diagnosis was a pre-requisite for inclusion in this paper.) At the time of interview, no interviewee was in a long-term relationship, two lived alone and one was temporarily living with family members. Brief vignettes are presented next, followed by results from the themes identified through reflexive thematic analysis.

\subsection{Female: Carly}

Carly is a 55-year-old heterosexual woman who was diagnosed with HIV in approximately 2010. In hindsight, Carly knew exactly when she contracted HIV but she was 
not formally diagnosed until almost a decade after this potential transmission date. Believing she had reached early menopause and that she had "fallen in love after a very messy divorce", Carly forewent any protective contraceptives with her new love. When he abruptly left two years into their relationship, she felt embarrassed but not alarmed. She subsequently learned that he was bisexual. Carly was diagnosed due to an AIDS-defining illness. Despite feeling 'off-color' for several years, no medical professional had thought it necessary to test Carly - a middle-aged heterosexual female and, therefore, outside the HIV-risk group-prior to the emergence of quite distinctive symptoms. A test revealed a very low CD4 count and Carly was referred to an urban public hospital infectious diseases (ID) clinic.

\subsection{Heterosexual Male: Jake}

Jake is a 41-year-old heterosexual male who was diagnosed with HIV in approximately 2010. Jake described himself as an intravenous drug user and 'a bit of a gigolo' around that time. Father to two adolescent children and separated since his diagnosis, Jake believed he was able to maintain his wellbeing through weight-lifting and long-distance running.

\subsection{Gay Male: Tony}

Tony is a 35-year-old gay male who was diagnosed with HIV in approximately 2010. Like many men in the gay community, Tony had regular tests and was diagnosed soon after becoming infected. Although shocked at the time, Tony was grateful for the advances in medications that meant his experiences would be different to the older cohort he saw at the HIV support services. Tony's family remained supportive, and although currently single, he strongly believed that the right partner would eventually come along.

\subsubsection{Theme 1: Access to Medical Services}

The three interviewees were all linked to HIV-specific medical services via ID clinics, but described quite disparate perceptions and experiences of these services. This, in turn, impacted their utilization of the services and indirectly their health.

When first diagnosed, Carly was referred to an urban public hospital ID clinic. She described hating this clinic but the alternative was her local doctor where she feared exposure among people she may know in her outer suburban place of residence.

Carly said she attends the ID clinic as infrequently as possible, travelling by taxi at considerable expense to herself. She confirmed that she dislikes these visits where she often feels publicly shamed:

"I always get the taxi driver to drop me well away from the clinic. I hate walking into that clinic where they're mainly men and they all stare at me. Sometimes there's a doctor I haven't seen before, and they always look shocked to see me because I'm older and I'm a woman. It's almost as if they're thinking, she should have known better. Probably I should have, but it stops me going as often as I should. Sometimes I cancel because I can't face the judgment, even if they're not judging me it feels like it."

Despite these uncomfortable experiences and feelings, Carly was always careful to maintain her medication regime, having experienced an AIDS-defining condition prior to diagnosis. She felt terrified of being hospitalized or having to go into care if her health declines.

Jake also described disliking going to an ID clinic, partly a legacy of his long-term hatred of medical services in general. "I hate going to the doctor," Jake stated early in the interview. "Even before HIV, I hated it and now I hate it even more." Jake attended an inner-city ID clinic rather than risk a local doctor becoming involved. Diagnosed when undergoing rehabilitation for drug use, he described having a panic attack the first time he had to attend the ID clinic:

"I stood at the elevator doors and I physically couldn't move to press the button.

I was sweating and in the end I went up the stairs, but then I couldn't get in the 
door. One of the nurses saw me shaking outside the clinic door and started to come out but I ran."

Jake admitted his HIV was not as well controlled as it could be because of his intermittent non-compliance when he skipped an appointment, but believed the physical activity would keep him well. Like Carly, he believed he did not belong at the ID clinic, which he described succinctly: "I hate seeing the people sitting round the clinic. Most of them are gay and some are even chatting like it's a social event. I don't belong there ..."

In contrast to Carly and Jake, Tony expressed no concerns about attending the ID clinic. Even before his diagnosis, Tony was very health conscious. He described his health regime: "I've always looked after my health, and I guess I was so used to having regular sexual health checks that now I don't have a problem with going to the clinic doctor for my HIV. Maybe I go too much? I'm a bit of a worrier, but that was even before my diagnosis."

Tony prided himself on keeping up-to-date with the latest medical advances in HIV, and would often raise things with his doctor that he had read. He stated that his doctor was always interested and receptive, making Tony feel like an equal partner in his healthcare.

\subsubsection{Theme 2: Social Support}

Social support, including lack of social support, featured strongly in the three interviewees' comments, but for very different reasons.

Carly described feeling lonely in outer suburbia. She tried attending a support group for women with HIV but found it 'too depressing'. The women had either been living with HIV since the 1980s and reminded her of where she was heading, or were young, newly diagnosed and more concerned about caring for children, relationships or getting pregnant. "There's no one I know of like me where I live, and the support group women were so different to me. Plus the group met near the ID clinic, and I hated going near that place," she confirmed.

Currently sharing her house with her daughter, son-in-law and their two young children while they are renovating their own home, Carly stated that rather than feeling supported by her family, she feels judged:

"My daughter knows because in the early days she was listed as my contact and one hospital did contact her and disclosed my diagnosis. She made me swear not to tell her husband and the kids. She's ashamed of me, and while she's supportive with any physical needs I may have, emotionally she's not there. I think it feels worse to have her so close and still not feel supported, than when she lives separately and I can at least pretend she cares. I have to go to another room to take my medications every day. She doesn't want her husband asking what they're for. Yeah, it's lonely ..."

Jake too described feelings of loneliness. He had not had a relationship since his diagnosis, partly because he was aware that his viral load was not as well controlled as it could be. He described the events after his diagnosis:

"My wife left me, which was a real kick to the ego. My kids accept things, even my mum has come to terms with it. I thought my sister had until I asked her if I could get the hospital to send my meds to the pharmacy where she works. She freaked and said everyone would know what they're for. I guess even family have limits with HIV."

Jake was clearly proud of maintaining his muscle-mass despite living with HIV but claimed this also deterred him from attending traditional HIV support services because he "gets hit on by gay males". He also had not disclosed at other venues frequented by heterosexual males-such as the weight-lifting venue-for fear of stereotyping and discrimination. He admitted these perceptions and beliefs limited his support networks, but still preferred non-disclosure and avoidance.

In contrast, Tony actively sought out social support from HIV services and his family. He described attending events such as World AIDS day to remind himself that he was part 
of a long-standing community. He believed: "It's a bit of a wake-up call to see the older ones there, and remember the battle they had decades ago to get to where we are today. They're the reason we've got support services which swing into action when you're diagnosed."

Tony's family were supportive too, although he remembered that his mother was angry at first that he was so careless. "My family have never made me feel awkward about being gay, but my mum was just furious that I caught this when I should have known better. She's right too, but we both got over it and now I've got an undetectable viral load and life's pretty good."

Although single at the moment, Tony believed online dating apps have helped normalize dating with HIV. "Apps like Grindr let you confidentially disclose HIV, which saves the awkward in-person conversation at a later date," he confirmed.

\subsubsection{Theme 3: Stigma}

All three interviewees had experienced stigma and took steps to avoid it, ranging from non-disclosure or selective disclosure to elimination of negative elements in their lives.

Carly acknowledged that she experienced minimal stigma because she practiced 'stigma avoidance'; that is, she does not tell anyone. Her perceived experiences with judgmental doctors and her daughter's shame made her determined to minimize opportunities of stigma as much as possible. She was quite resigned to losing sources of social support through this form of stigma-avoidance, but could see no alternative. She confirmed:

"I often wonder if I went to my neighbor's house for a cup of tea and told her I was HIV positive, would she be horrified? Sometimes I want to test it just to have someone to talk to, but I know I'm never going to find out because I'm not going to tell anyone. The risk is too much. At the moment it's me, my daughter, the ID clinic and the hospital pharmacy. No one else in the world knows and that's the way it's going to stay."

Jake was philosophical about the common perceptions of HIV as a gay disease and the resultant stereotyping he experienced, as he explained:

"I'm off drugs now, but even if I wasn't, I wouldn't go near my druggie friends. They still talk about HIV as a 'poofter's disease' and so in their minds that would make me a poofter. I think it's worse for a heterosexual man because there's not so many of us around and we're immediately labelled as something we're not."

He had experienced, first-hand, the stigma associated with HIV when he was diagnosed in rehabilitation and they immediately sent him off to another facility. "It was as if HIV was the lowest of low, and so I needed to be removed from even the druggies," he stated with traces of residual bitterness.

Jake described having come to terms with the stigma, until his sister refused his request for medication delivery. It was then he realized that HIV stigma was still around and destructive. That sealed his decision to opt for non-disclosure as a means to combat stigma.

Like Carly and Jake, Tony described being very aware of stigma round his diagnosis, but he chose to ignore it and focus on those support networks that were non-judgmental. He freely acknowledged that he was lucky to have these supports to buffer the stigma that he had seen others experience:

"If I didn't have a supportive family and other social supports, I probably would have considered taking my life like I've seen quite a few men do when they're diagnosed and rejected. I'm not proud of being HIV, but I don't hide it. The stigma is out there and sometimes it can catch you unawares, like the old friend who learns and suddenly won't hug you, or the comments on some discussion boards about 'must be clean' as if HIV is dirty. So old fashioned, but still hurtful so I choose to cut myself off from those experiences and stick with the good ones." 


\subsubsection{Theme 4: Mental Health}

All three interviewees described experiences of reduced mental health associated with their HIV diagnosis.

Carly confirmed being diagnosed with both depression and anxiety over the last decade, potentially exacerbated by the lack of supports and someone she could talk freely with:

"I had a bad marriage when I was on anti-depressants, but once that was over I thought my mood was pretty stable. Even when my ex-partner left and I kept getting sick, I was still stable. HIV changed that, and I think it's because I've got no one to talk to. The thought of a therapist knowing my secret terrifies me, so when the ID clinic doctors say how are you, I just smile and say fine. I guess they didn't believe me because they still prescribed medications for my moods and tried to get me to a therapist. I take the tablets, but the therapist is not happening."

Having rarely taken medications prior to his HIV diagnosis, Jake struggled to come to terms with the need to take daily medications potentially for the rest of his life. Rather than add to these daily medications, he adamantly refused to take the anti-depressants that the doctors prescribed when he was first diagnosed:

"I know I pumped chemicals into my body with the drugs, but that felt like choice - even though I was an addict so the choice bit is debatable. Now they were telling me I had to take tablets for the rest of my life and I hated it. That's what really got me down, so they wanted to give me anti-depressants to get over that. I refused."

Jake acknowledged he still became quite down at times, and turned to exercise to counter that. He described running in particular as offering a 'high' that could get him over any negative moods. Yet, even exercise could not fix everything, as he described: "The down-side to needing exercise is the blackness that settles on me when I'm prevented from running or weight-lifting." When an injury prevented him from either activity for several weeks, he experienced a drop in mood that verged on suicidal ideation. He still worried about how he would cope when too old to run.

Tony also worried about the future, but acknowledged he was a worrier even before the HIV diagnosis. He did end up on anti-anxiety meds when he was first diagnosed:

"I'm not sure I needed them medically, but at the time I think the doctors felt it would be more anxiety-provoking not to prescribe them than prescribe them. I saw a therapist too, but he ended up telling me I was incredibly well-adjusted. Again, just me over-thinking things. I thought I should need all this mental health support but in reality I didn't. I had my family and my friends and now my HIV community, and that seems to be enough at the moment. Ask me again if I get really sick, but I'm doing my best to avoid that."

Tony described his mental health now as 'never better', partly due to his acceptance that as long as he adhered to the increasingly sophisticated medications available, looked after his health, remained linked to a supportive community and avoided 'toxic relationships', he would be fine.

\section{Discussion}

The preceding case reports support the idea that living with HIV can result in different lived experiences depending on gender and sexuality. All three interviewees described different experiences related to access to medical services, social support, stigma, and mental health. These findings are discussed next within the context of the current literature. 


\subsection{Access to Medical Services}

The interviewees described quite different experiences of access to medical services. As a minority group among people with HIV, the female Carly was diagnosed late, felt ashamed and out-of-place at medical services, but maintained strict medication compliance. Heterosexual Jake, also a minority group among people with HIV, was diagnosed within the context of another condition (substance abuse) rather than presenting for HIV, and described a reluctance to visit medical services tailored more towards majority HIV population groups. This reluctance contributed to lapses with medication compliance. Tony, part of the gay community and the majority HIV population group in Australia, was diagnosed early due to routine testing, felt an equal partner in his HIV treatment, and maintained strict medication compliance.

Increasingly sophisticated modern HIV treatments now allow a person with HIV to maintain a high quality of life with undetectable viral loads and no visible signs of HIV [13]. Previously a death sentence for many people, HIV is now considered a treatable chronic disease provided a person maintains medication compliance [14]. Successful treatment also depends on a person being diagnosed in a timely manner and maintaining contact with suitable medical services. Results reported in this paper indicate gender and sexuality can lead to different responses in this area.

In Australia, the focus on HIV as predominately affecting MSM has meant heterosexual females and heterosexual males may fall outside the routine screening, be less likely to share their HIV status with healthcare providers outside of their main HIV medical service, and, therefore, miss the opportunity for timely and regular interventions [7,15]. A longitudinal study conducted in middle-income and high-income countries identified higher rates of non-retention in care among heterosexual males, opening the door for poorer virus control and potentially poorer overall health [7]. Findings from this international study also identified more differences existed between heterosexual males and MSM than between heterosexual males and women in a number of health-related outcomes. In Australia, there is evidence that women's reduced visibility and potential reluctance to engage in medical services and social networks that focus on, and are frequented by, MSM, the largest HIV group, means they are more likely to feel isolated and 'slip through the cracks' medically and socially [15].

Another key difference identified in the case reports presented in this paper was the greater health literacy of the gay male as compared to the heterosexual female and male. This finding is mirrored by other studies that report MSM can demonstrate greater understanding of their medications, greater perceived comfort in discussing their challenges with medical professionals and greater overall involvement in their care [7].

Australia's early response to the HIV crisis in the 1980s and 1990s has been described as so successful because the gay community mobilized and developed their own strategies to reduce HIV transmission and care for those affected [16]. It therefore remains a priority to continue working towards minimizing any perceived disparities between the overlapping but unique needs of heterosexual females and males in this ongoing pandemic [7].

\subsection{Social Support}

The interviewees also described quite different sources of, and access to, social support. The female Carly described feelings of loneliness, shame and lack of support, largely brought about by a determination not to disclose her HIV status and experiences of real and perceived criticisms among those who, by necessity, knew of her diagnosis. The heterosexual male Jake described the role of selective disclosure and severance of old networks for self-protection, which, by necessity, limited his sources of social support. Both Carly and Jake described not fitting in with traditional HIV support services, which further limited sources of social support, especially as both also described conditional support from family members who knew of their diagnosis. In contrast, the gay male Tony embraced the long-standing HIV support services available, chose to ignore or separate himself from judgmental sources, and was surrounded by a supportive family and friendship network. 
For many people diagnosed with HIV, they must come to terms with living with a treatable, but still incurable disease, as well as the personal and social changes that may result. An HIV diagnosis may abruptly change family and friendship structures, especially where lingering perceptions remain that HIV diagnosis is associated with 'lifestyle' choice [17]. There is evidence that social support can promote positive coping strategies among people with HIV [18], with those people who perceive little or no social support adopting maladaptive coping strategies more often than those who perceive greater social support. Evidence of gender differences in seeking social support broadly suggests that women may be more likely to seek social support compared to males [18], but this was not evident in the female interviewee in this report. Instead, the gay male showed the highest degree of social connectivity, perhaps reflective of being a member of the majority HIV group in Australia. Avoiding social support can also be strongly related to experiences of perceived or anticipated stigma, which may account for both the female and the heterosexual male deliberately reducing their potential support networks and, thus, their sources of both emotional support and tangible support with its flow-on effect to ongoing and regular medical care.

\subsection{Stigma}

Stigma has been described as one of the most challenging consequences reported among people living with HIV [17], but there is evidence that it may be perceived differently among women, heterosexual males and MSM [19]. Strongly connected to their descriptions of social support, both Carly and Jake chose to minimize experiences of stigma thorough non-disclosure or selective, limited disclosure. Tony, acknowledging the inevitability of stigma due to lingering perceptions of HIV and risk behaviors associated with it, similarly chose to separate himself from negative experiences. The key difference was that Tony retained a strong enough social network to buffer and compensate for the removal of any sources of discrimination and perceived or anticipated stigma.

Stigma has played a key role in the medical and social history of HIV [20]. Stigma can be defined as an individual's inability to meet social and cultural role expectations [21] and is strongly interwoven with negative labelling, stereotyping and an eventual 'othering' that separates 'them' from 'us' [22]. Stigma can take the form of actual discrimination, resulting in the stigmatized person existing on the fringes of society, or perceived stigma, where they live in fear or anticipation of rejection [21]. While gay men are typically described as sexual minority groups and sometimes relegated to the fringes of society, among those living with HIV in Australia, it is the heterosexual women and men who form minority groups. According to a US study, these minority groups within the HIV population of higher income countries can potentially be at risk of experiencing greater perceived or anticipated HIV stigma than those who identify as part of a sexual minority but part of the dominant cohort of HIV [14]. The authors of this study posited that over the decades, the sexual minority groups of gay men have been the target of ongoing health campaigns, resources and support networks for HIV and have thus developed different attitudes related to anticipated HIV stigma. However, they may be at greater risk of social stress around the intersection of their identity as a gay male where it conflicts with the social and cultural norms of their immediate environment. In this study, the gay male Tony did not report any identity conflict in his environment, possibly reflecting some of the social advances made by the gay movement in Australia.

In contrast, the heterosexual male Jake did describe experiences of stigma, in keeping with the literature supporting differences in experiences for gay and heterosexual men living with HIV in developed countries [23]. When exploring the sexual identity of heterosexual men in Australia, Persson [24] suggested that heterosexual men with HIV felt they no longer belonged to the heterosexual community, but did not want to identify as gay, and so became disconnected from any community that could buffer some of the negative impacts of stigma. A flow-on effect is evidence that heterosexual males report 
greater perceived negative reactions from people in their social environment [23], thus consolidating feelings of not belonging.

Irrespective of gender or sexuality, there is evidence that non-disclosure of HIV status to avoid experiences of stigma, or anticipated stigma, can be linked to reduced social support and poorer health outcomes [19]. When exploring gender differences in HIV disclosure and stigma, Geary et al. [19] identified that women displayed higher levels of internalized stigma than men and were less likely to disclose their HIV status to partners and spouses. Internalized stigma, often arising from societal expectations and perceived moral judgment of others, can lead to feelings of shame, guilt, lowered self-esteem, isolation and mental health challenges $[19,25]$, similar to the feelings reported by Carly, the female heterosexual in this paper. Internalized stigma requires ongoing vigilance to anticipate and manage potential interactions, thus becoming a psychosocial stressor even when no discriminatory treatment is experienced [26]. These feelings can be compounded by experiences of sexism and gender discrimination reported by women in general and the subsequent impacts on physical and mental health [27].

\subsection{Mental Health}

Linked to both social support and stigma is mental health. A common perception following the introduction of increasingly sophisticated medications from the 1990s onward was that people with HIV could live longer, healthier and 'normal' lives [21]. While Carly, Jake and Tony described varying levels of physical wellness, mental health was mentioned to some degree by all three. Carly acknowledged feelings of anxiety and depression, which she related to the lack of anyone to talk to or care about her as a person. She refused to see a therapist who could have provided someone to talk to, opting instead to take the anti-depressants prescribed. Jake also acknowledged mental health concerns, but chose to 'self-medicate' through vigorous exercise to relieve the blackness. Ironically, Tony believed he should have had mental health issues and was pleasantly surprised to discover he did not.

Studies have consistently reported that people with HIV do experience higher rates of poor mental health compared to the general population [28]. This includes research among diverse groups such as youth, adult MSM, older adults, people who inject drugs and women. However, research also indicates that the mental health needs among people living with HIV can vary by gender [29]. While general population research suggests that women are more susceptible to internalizing mental disorders and that substance abuse disorders are more common among males [29], this may not always be applicable to people with HIV. For example, anxiety and depression have been identified as more likely to occur with heterosexual males with HIV and substance abuse disorders with heterosexual females with HIV [29], while other research suggests women with HIV remain at a high risk of anxiety and depression [4]. Irrespective of contradictory evidence, data from the Australian HIV Futures 9 clearly indicate that people with HIV report higher rates of current or past diagnoses of depression (55.2 per cent) and anxiety (43 per cent) compared to the general population [4].

While social support has been identified as a moderator for mental health issues, stigma has been identified as a stressor, irrespective of gender [17]. This suggests an individual's mental health when living with HIV is affected not just by gender and sexuality, but rather a complex intersection of factors related to social and cultural norms.

\section{Limitations}

A limitation of this study is that participants self-selected and, therefore, were only representative of three groups of people living with HIV in Australia. Given the obstacles of non-disclosure and stigma, some groups may not have been accessed, or were reluctant to participate. In particular, the unique experiences of lesbian women and transgender individuals are not represented in this paper. Further study among these groups is recommended to achieve an in-depth consideration of gender identity, sexuality and living with 
HIV. In addition, race and ethnicity was not discussed in this paper. It is acknowledged that people from ethnically diverse backgrounds in Australia would add another layer of complexity to the question of gender, sexuality and living with HIV, and this also is in need of further exploration. Finally, while reflexive thematic analysis is a recursive process that recognizes researcher subjectivity, it is acknowledged that coding is a subjective process. The researcher at all points endeavored to reflect on their assumptions and how they might shape or limit their coding, and critically reflected on the findings within the wider field of literature.

\section{Conclusions}

This paper explored three gendered experiences of living with HIV in Australia. Each case report provided a snapshot of different experiences of diagnosis and access to medical services; social support including family; real, perceived and anticipated stigma and disclosure patterns; and mental health. When juxtaposed against the current literature, these findings reinforce the need for a targeted approach to the needs of different cohorts living with HIV in the twenty-first century. Acknowledging and addressing that there is no one HIV response, it becomes imperative to understand the different facets of a person's lived experience in order to maintain equity for all people living with HIV.

\section{Implications}

This has implications for the need to develop interventions to improve timely diagnosis and ongoing treatment and support among women and heterosexual males who form the minority groups within the HIV population of Australia. This paper draws attention to the need for service providers to incorporate knowledge of stigma and internalized stigma into existing education and health promotion initiatives promoting safe HIV testing, disclosure and treatment. On a wider scale, there is a need for ongoing public education initiatives to address lingering negative perceptions of HIV and normalizing HIV as a treatable chronic illness in the twenty-first century.

Funding: This research received no external funding.

Institutional Review Board Statement: This study was approved by the Monash University Human Research Ethics Committee.

Informed Consent Statement: Informed consent was obtained from all subjects involved in this study.

Data Availability Statement: Restrictions apply to the availability of these data due to privacy and confidentiality.

Conflicts of Interest: The author declares no conflict of interest.

\section{References}

1. UNAIDS. Global HIV \& AIDS Statistics-2020 Fact Sheet. Available online: https:/ /www.unaids.org/en/resources/fact-sheet\#: $\sim\{\}:$ text=GLOBAL\%20HIV\%20STATISTICS,infected\%20with\%20HIV\%20in\%202019 (accessed on 22 May 2021).

2. UNAIDS. Gender. Available online: https:/ / www.unaids.org/en/topic/gender (accessed on 22 May 2021).

3. UN Women. Facts and Figures: HIV and AIDS. Available online: https://www.unwomen.org/en/what-we-do/hiv-and-aids/ facts-and-figures (accessed on 22 May 2021).

4. Power, J.; Amir, S.; Brown, G.; Rule, J.; Johnson, J.; Lyons, A.; Bourne, A.; Carman, M. HIV Futures 9: Quality of Life Among People Living with HIV in Australia, Monograph Series Number 116; The Australian Research Centre in Sex, Health and Society, La Trobe University: Melbourne, Australia, 2019.

5. amfAR. Statistics: Women and HIV/AIDS. Available online: https://www.amfar.org/about-hiv-and-aids/facts-and-stats / statistics--women-and-hiv-aids/ (accessed on 22 May 2021).

6. amfAR. Statistics: Worldwide. Available online: https://www.amfar.org/About-HIV-and-AIDS/Facts-and-Stats/Statistics-Worldwide/ (accessed on 22 May 2021).

7. Okoli, C.; Van de Velde, N.; Brough, G.; Hardy, W.D.; Corbellis, G.M.; Allan, B.; Muchenje, M.; Castellanos, E.; Young, B.; Eremin, A.; et al. Differences in HIV treatment experiences, perceptions, and behaviors by gender and sexual orientation in 25 middle-income and high-income countries: Findings from the 2019 Positive Perspectives Survey. Popul. Med. 2020, 2, 1-13. [CrossRef] 
8. Australian Federation of AIDS Organisations. HIV Statistics. Available online: https://www.afao.org.au/about-hiv/hiv-inaustralia/ (accessed on 22 May 2021).

9. Thorpe, R.; Power, J.; Brown, G.; Lyons, A.; Dowsett, G.W.; Lucke, J. HIV Futures 8: Women Living with HIV in Australia; The Australian Research Centre in Sex, Health and Society, La Trobe University: Melbourne, Australia, 2017.

10. SurveyMonkey. Available online: https:/ / www.surveymonkey.com/ (accessed on 13 June 2021).

11. Braun, V.; Clarke, V. Can I use TA? Should I use TA? Should I not use TA? Comparing reflexive thematic analysis and other pattern-based qualitative analytic approaches. Couns. Psychother Res. 2021, 21, 37-47. [CrossRef]

12. Braun, V.; Clarke, V. Using thematic analysis in psychology. Qual. Res. Psychol. 2006, 3, 77-101. [CrossRef]

13. UNAIDS. Undetectable = Untransmittable. Available online: https://www.unaids.org $/$ sites $/$ default $/$ files $/ \mathrm{media}$ asset $/$ undetectable-untransmittable_en.pdf (accessed on 22 May 2021).

14. Price, D.M.; Fikslin, R.A.; Goldberg, A.J.; Gesselman, A.N.; Loubriel, J.C.; Brooks, J. Sexual orientation and differences in HIV cognitions. Personal. Individ. Differ. 2020, 152, 1-7. [CrossRef]

15. Moreira, C.; Boughey, A.; Ryan, K.E.; Higgins, N.; Rotty, J.; West, M.; Hellard, M.; Stoove, M.; El-Hayek, C. Two decades of surveillance data show late presentation among a diverse group of women diagnosed with HIV in Victoria, Australia. Aust. N. Z. J. Public Health 2019, 43, 413-418. [CrossRef] [PubMed]

16. Sendziuk, P. Learning to Trust: Australian Responses to AIDS; University of New South Wales Press Ltd: Sydney, Australia, 2003.

17. Hutton, V.E.; Misajon, R.; Collins, F.E. Subjective wellbeing and 'felt' stigma when living with HIV. Qual. Life Res. 2013, 22, 65-73. [CrossRef] [PubMed]

18. Li, L.; Lin, C.; Liang, L.-J.; Ji, G. Exploring coping and social support with gender and education among people living with HIV in China. AIDS Behav. 2016, 20, 317-324. [CrossRef] [PubMed]

19. Geary, C.; Parker, W.; Rogers, S.; Haney, E.; Njihia, C.; Haile, A.; Walakira, E. Gender differences in HIV disclosure, stigma, and perceptions of health. AIDS Care 2014, 26, 1419-1425. [CrossRef] [PubMed]

20. Herek, G.; Glunt, E. An epidemic of stigma: Public reactions to AIDS. Am. Psychol. 1988, 43, 886-891. [CrossRef] [PubMed]

21. Green, G. The End of Stigma? Changes in the Social Experiences of Long Term Illness; Routledge: Oxford, UK, 2009.

22. Link, B.G.; Phelan, J.C. Conceptualizing stigma. Annu. Rev. Sociol. 2001, 27, 363-385. [CrossRef]

23. Brener, L.; Wilson, H.; Slavin, S.; de Wit, J. The impact of living with HIV: Differences in experiences of stigma for heterosexual and homosexual people living with HIV in Australia. Sex. Health 2013, 10, 316-319. [CrossRef] [PubMed]

24. Persson, A. The undoing and doing of sexual identity among heterosexual men with HIV in Australia. Men Masc. 2012, 15, 311-328. [CrossRef]

25. Brown, M.J.; Serovich, J.M.; Laschober, T.C.; Kimberly, J.A.; Lescano, C.M. Ways of coping and perceived HIV-related stigma among people living with HIV: Moderation by sex and sexual orientation. Psychol. Health Med. 2019, 25, 867-878. [CrossRef] [PubMed]

26. Ziersch, A.; Walsh, M.; Baak, M.; Rowley, G.; Oudih, E.; Mwanri, L. "It's not an acceptable disease": A qualitative study of HIV-related stigma and discrimination and impacts on health and wellbeing for people from ethnically diverse backgrounds in Australia. BMC Public Health 2021, 21, 779-794. [CrossRef] [PubMed]

27. Logie, C.H.; Wang, Y.; Lacombe-Duncan, A.; Wagner ACKaida, A.; Conway, T.; Webster K de Pokomandy, A.; Loutfy, M.R. HIV-related stigma, racial discrimination, and gender discrimination: Pathways to physical and mental health-related quality of life among a national cohort of women living with HIV. Prev. Med. 2018, 107, 36-44. [CrossRef]

28. Remien, R.H.; Stirratt, M.J.; Nguyen, N.; Robbins, R.N.; Pala, A.N.; Mellins, C.A. Mental health and HIV/AIDS: The need for an integrated response. AIDS 2019, 33, 1411-1420. [CrossRef] [PubMed]

29. Fang, L.; Chuang, D.-M.; Al-Raes, M. Social support, mental health needs, and HIV risk behaviors: A gender-specific, correlation study. BMC Public Health 2019, 19, 1-8. [CrossRef] [PubMed] 